\title{
Konsep Bangunan Pintar pada Perancangan Wahana Permainan dan Hiburan Berbasis Teknologi Digital di Surabaya
}

\author{
Afifah Marintan Nuriyana ${ }^{1}$, Failasuf Herman Hendra ${ }^{2}$, Sigit Hadi Laksono ${ }^{3}$ \\ 1,2,3 Jurusan Arsitektur, Fakultas Teknik Sipil dan Perencanaan, Institut Teknologi Adhi Tama Surabaya \\ Email: 1intannuriyana@gmail.com
}

\begin{abstract}
The high rate of the economy in Surabaya can affect the high level of employee workload and student learning load which results in the people of Surabaya becoming even busier. The higher the level of activity, the higher the stress level. The way to relieve stress is to play. The most popular types of games today are games with digital technology. These types of games are virtual reality games, augmented reality, mixed reality, motion sensors and neuro-gaming technology. To accommodate the needs of digital technology-based game play activities, so the construction for Games and Entertainment Facilities Based on Digital Technology in Surabaya as a recreational tourist spot that can relieve a person's stress. The research method used is descriptive research. Data collection techniques were obtained from the results of field case studies and literature case studies. The identification process produces data and information which is then analyzed. The analysis produces the required themes and concepts. The theme used is High Tech Architecture, which is a design that requires the use of the latest and latest technology in building facade materials and building structures. The concept used is Smart Building, which is a design that uses an automation technology system that can minimize the use of electricity to make it more energy efficient and environmentally friendly. This concept emphasizes security and security of building users. The smart building concept macro is divided into three micro concepts, namely layout, shape, and space. The micro layout concept used is responsive. The micro form concept used is expressive. Meanwhile, for the micro, the concept of space used is futuristic and efficient.
\end{abstract}

Keywords: Games and Entertainment; High Tech Architecture; Smart Building.

\begin{abstract}
Abstrak. Tingginya laju perekonomian di Surabaya dapat mempengaruhi tingginya tingkat beban kerja para karyawan dan beban belajar para pelajar yang mengakibatkan masyarakat Surabaya menjadi semakin sibuk. Semakin tinggi tingkat kesibukan, maka semakin tinggi pula tingkat stress. Cara untuk menghilangkan rasa stress adalah bermain. Jenis permainan paling populer saat ini adalah permainan berteknologi digital. Jenis permainan tersebut adalah permainan virtual reality, augmented reality, mixed reality, motion sensor dan neuro-gaming technology. Untuk mewadahi kebutuhan aktivitas bermain permainan berteknologi digital, maka dibangunnya Wahana Permainan dan Hiburan Berbasis Teknologi Digital di Surabaya sebagai tempat wisata rekreasi yang dapat menghilangkan rasa stress seseorang. Metode penelitian yang digunakan adalah penelitian deskriptif. Teknik pengumpulan data didapatkan dari hasil studi kasus lapangan dan studi kasus literatur. Proses identifikasi menghasilkan data dan informasi yang kemudian dianalisis. Analisis tersebut menghasilkan tema dan konsep yang dibutuhkan. Tema yang digunakan adalah Arsitektur High Tech yaitu suatu desain yang membutuhkan penggunaan teknologi terbaru dan mutakhir pada material fasad bangunan maupun struktur bangunan. Konsep yang digunakan adalah Bangunan Pintar yaitu suatu desain yang menggunakan sistem teknologi otomatisasi yang dapat meminimalisir penggunaan listrik agar lebih hemat energi dan ramah lingkungan. Konsep ini sagat mementingkan keamanan dan keyamanan pengguna bangunan. Makro konsep bangunan pintar dibagi menjadi tiga mikro konsep yaitu tatanan lahan, bentuk, dan ruang. Mikro konsep tatanan lahan yang digunakan adalah responsif. Mikro konsep bentuk yang digunakan adalah ekspresif. Sedangkan, untuk mikro konsep ruang yang digunakan adalah futuristik dan efisien.
\end{abstract}

Kata Kunci: Wahana Permainan dan Hiburan; Arsitektur High Tech; Bangunan Pintar.

\section{Pendahuluan}

Tingkat pertumbuhan ekonomi yang pesat menjadikan kota Surabaya sebagai kota terbesar kedua di Indonesia. Perekonomian di Surabaya didukung oleh sektor perdagangan, bisnis, industri, dan pariwisata. Masing-masing dari sektor tersebut tiap tahunnya semakin berkembang pesat, sehingga meningkatkan segi perekonomian masyarakat. Pertumbuhan dan perkembangan ekonomi ini juga 
diiringi dengan tingkat beban kerja karyawan yang tinggi. Karyawan akan bekerja terlalu berlebihan untuk memenuhi standar dan target kerja yang telah ditetapkan. Pelajar juga tidak luput dari tuntutan untuk mendapatkan nilai dan prestasi yang membanggakan agar dapat bersaing di duna kerja. Faktor tuntutan pekerjaan dan pendidikan menyebabkan masyarakat menjadi semakin sibuk. Semakin tinggi tingkat kesibukan, maka semakin tinggi pula tingkat kelelahan dan stress yang diderita.

Bekerja dan belajar menyita banyak waktu, tenaga dan pikiran, sehingga masyarakat membutuhkan tempat hiburan. Tempat hiburan ini berfungsi untuk menenangkan pikiran, menghilangkan rasa stress, mengusir rasa bosan, dan melepaskan kejenuhan. Sebuah hiburan bagi manusia dapat membuat hati, pikiran dan badan terasa lebih tenang dan segar.

Salah satu cara untuk menghilangkan rasa stress adalah dengan bermain. Pilihan masyarakat dalam menghilangkan rasa stress dipengaruhi oleh perkembangan Ilmu Pengetahuan dan Teknologi saat ini. Jenis permainan yang telah berkembang saat ini adalah permainan berteknologi digital (komputerisasi). Untuk memenuhi kebutuhan masyarakat akan tempat hiburan maka, didirikannya tempat wisata rekreasi Wahana Permainan dan Hiburan Berbasis Teknologi Digital di Surabaya yang sangat diperlukan.

Wahana Permainan dan Hiburan Berbasis Teknologi Digital di Surabaya diciptakan untuk mengikuti perkembangan teknologi digital terkini pada setiap fasilitasnya untuk menarik minat pengunjung. Jenis permainan berteknologi yang disediakan adalah tekonologi game digital berbasis virtual yaitu virtual reality, augmented reality, mixed reality, motion sensor dan neuro-gaming technology.

\section{Tinjauan Pustaka}

\section{Arsitektur High Tech}

Menurut Colin Davies, dalam bukunya High Tech Architecture, pengertian high tech dalam arsitektur berbeda dengan pengertian high tech dalam industri. Bila dalam industri pengertian high tech diartikan sebagai teknologi canggih seperti elektronik, komputer, robot, chips, dan sejenisnya. Sedangkan dalam arsitektur, high tech diartikan sebagai suatu aliran arsitektur yang bermuara pada ide gerakan arsitektur modern yang membesar-besarkan kesan struktur dan teknologi suatu bangunan. Karakteristik yang menjadi referensi arsitektur high tech adalah bangunan yang terbuat dari material sintetis seperti logam, kaca dan plastik (Telew \& Lintong, 2011).

Kesimpulan dari penjabaran diatas, maka diperoleh pengertian bahwa Arsitektur High Tech adalah suatu desain yang membutuhkan penggunaan teknologi terbaru dan mutakhir pada material fasad bangunan maupun struktur bangunan.

\section{Bangunan Pintar}

Menurut Afandi (2007), bangunan adalah suatu susunan elemen-elemen yang membentuk fungsi untuk mewadahi aktivitas manusia dengan segala komponen yang dibutuhkan dalam aktivitasnya. Ia memiliki bentuk dan dimensi yang dapat menaungi dengan memiliki kekakuan dan kekokohan yang dapat melindungi manusia dan segala aktifitas di dalamnya dari segala gangguan. Karena bangunan berfungsi untuk mewadahi aktivitas manusia maka ia harus mempunyai keadaan yang dibutuhkan oleh manusia yaitu kenyamanan, keamanan, dan efisiensi, serta kebutuhan-kebutuhan manusia yang lain (Pratasik \& Sangkertadi, 2011).

Menurut Kamus Besar Bahasa Indonesia, pintar adalah pandai; cakap; cerdik; banyak akal; mahir melakukan atau mengerjakan sesuatu (Depdiknas, 2008).

Kesimpulan dari penjabaran diatas, maka diperoleh pengertian bahwa Bangunan Pintar adalah suatu tempat yang berfungsi untuk mewadahi aktivitas manusia yang didesain dengan menggunakan sistem teknologi otomatisasi yang dapat meminimalisir penggunaan listrik agar lebih hemat energi. Namun, tetap memperhatikan kenyamanan, keamanan, dan efisiensi.

\section{Wahana Permainan dan Hiburan Berbasis Teknologi Digital}

Menurut Kamus Besar Bahasa Indonesia, wahana adalah kendaraan; alat pengangkut; alat atau sarana untuk mencapai tujuan (Depdiknas, 2008). Menurut Hurlock (1978), permainan adalah proses aktivitas fisik atau psikis yang menyenangkan dan menggembirakan (Pustakapaud, 2016). Menurut Schrum, dalam bukunya The Psychology of entertainment: concepts and application, hiburan adalah 
suatu aktivitas yang dirancang untuk memberi kesenangan dan relaksasi kepada orang lain, dimana audience bersifat pasif (one way communication). Dengan demikian, segala sesuatu yang bersifat menyenangkan dan membuat rileks secara subyektif termasuk sebagai hiburan atau entertainment (Phoibe, 2015).

Menurut Kamus Besar Bahasa Indonesia, berbasis berasal dari kata basis yang memiliki arti asas; dasar. Maka Arti kata berbasis adalah mempunyai basis. Berbasis juga berarti berdasarkan pada (Depdiknas, 2008). Menurut Miarso (2007), teknologi adalah suatu bentuk proses yang meningkatkan nilai tambah. Proses yang berjalan dapat menggunakan atau menghasilkan produk tertentu, dimana produk yang tidak terpisah dari produk lain yang sudah ada. Hal itu juga menyatakan bahwa teknologi merupakan bagian integral dari yang terkandung dalam sistem tertentu (Pambudi, 2015). Menurut Kamus Besar Bahasa Indonesia, digital memiliki arti berhubungan dengan angka-angka untuk sistem perhitungan tertentu; berhubungan dengan penomoran (Depdiknas, 2008).

Kesimpulan dari penjabaran diatas, maka diperoleh pengertian bahwa Wahana Permainan dan Hiburan Berbasis Teknologi Digital merupakan tempat yang menawarkan aktivitas yang menyenangkan dan merelaksasi penggunanya dengan menggunakan suatu produk berupa alat permainan yang mempunyai basis komputerisasi terbaru.

\section{Metode Penelitian}

Metode penelitian yang digunakan adalah penelitian deskriptif, penelitian ini berkaitan dengan pengumpulan data untuk memberikan gambaran tentang suatu gejala secara sitematis dan akurat (Gambar 1). Teknik pengumpulan data didapatkan dari hasil studi kasus lapangan dan studi kasus literature. Metode pengumpulan data studi kasus lapangan diperoleh dari survey secara langsung ke lokasi obyek yang dipilih yaitu Jatim Park 3 Batu, Surabaya Carnival Surabaya, WTC \& WTC E-Mall Surabaya, dan ITS Research Center Surabaya. Metode pengumpulan data studi kasus literature diperoleh melalui media internet, obyek yang dipilih adalah VR Theme Park China, dan Campus Palma Altas Spanyol.

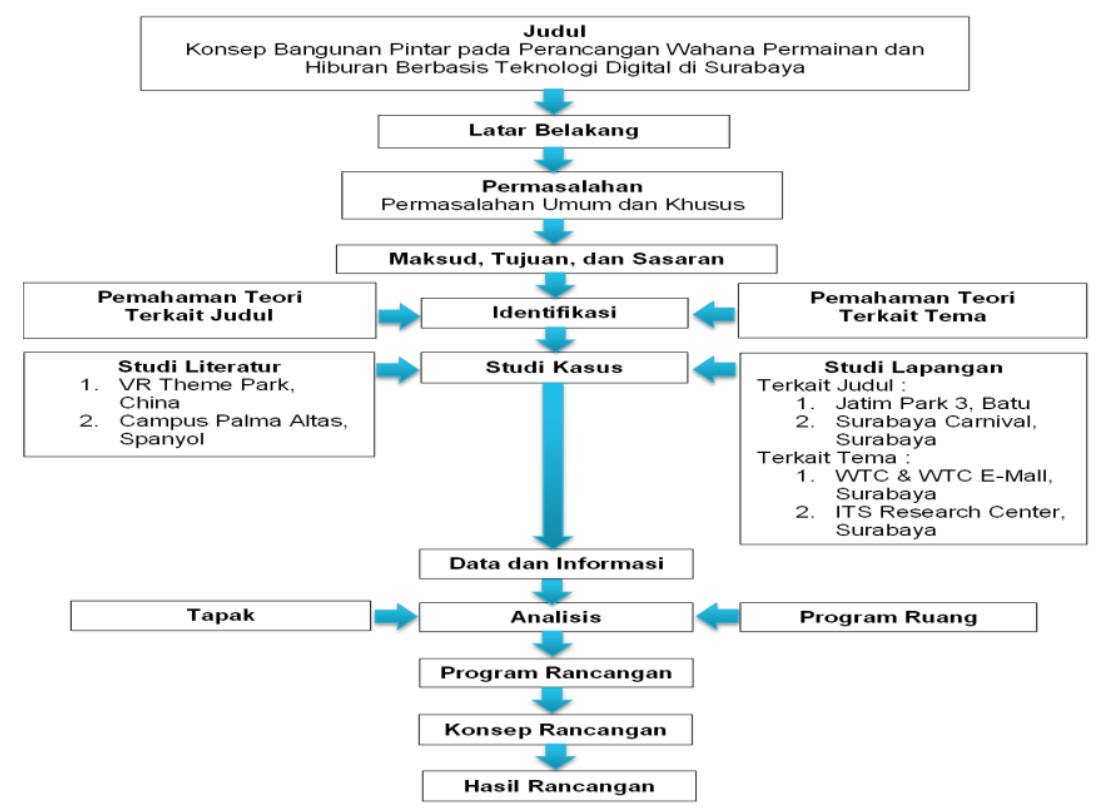

Gambar 1. Diagram Metodologi

\section{Pembahasan Studi Banding}

Studi banding dibedakan menjadi dua macam yaitu studi banding lapangan dan studi banding literatur. Dimana studi banding lapangan mengambil objek di Jatim Park 3 Batu, Surabaya Carnival Surabaya, WTC \& WTC E-Mall Surabaya, dan ITS Research Center Surabaya (Gambar 2 dan 3). Untuk studi banding literatur mengambil objek di VR Theme Park China, dan Campus Palma Altas Spanyol 
(Gambar 4). Alasan pemilihan objek-objek studi banding ini dikarenakan adanya kemiripan dengan objek penelitian yaitu jenis permainan yang digunakan adalah permainan virtual reality, augmented reality, mixed reality, motion sensor dan neuro-gaming technology, dan tema yang digunakan adalah arsitektur high tech.

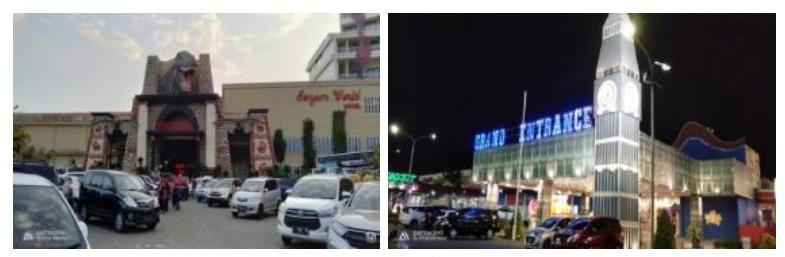

Gambar 2. Jatim Park 3, Batu (Kiri) dan Surabaya Carnival, Surabaya (Kanan)

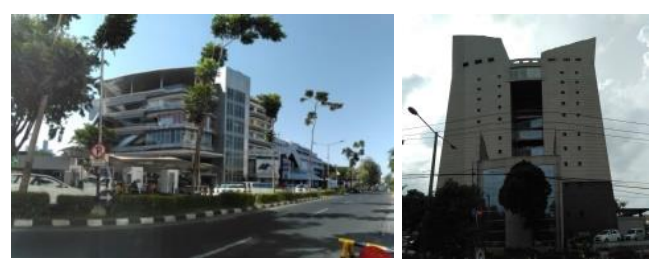

Gambar 3. WTC \& WTC E-Mall, Surabaya (Kiri) dan ITS Research Center, Surabaya (Kanan)
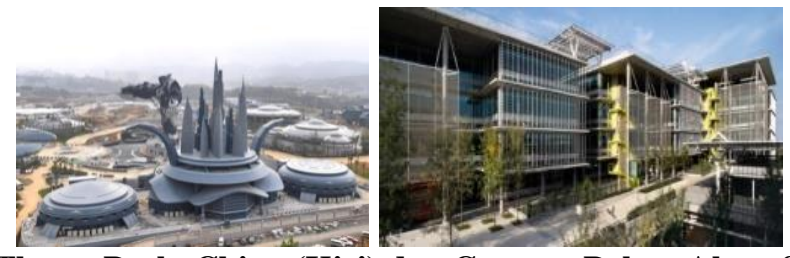

Gambar 4. VR Theme Park, China (Kiri) dan Campus Palma Altas, Spanyol (Kanan)

Hasil observasi dari studi banding lapangan dan literatur tersebut menghasilkan kesimpulan yaitu: (1) Dapat mengatur tata massa bangunan dan ruang terbuka hijau dengan baik. (2) Sebagai tempat wisata rekreasi sebaiknya membuat bentuk bangunan yang unik dan ekspresif. (3) Menciptakan suasana ruang yang seakan-akan berada di masa depan. Kesimpulan tersebut dapat digunakan sebagai acuan dan contoh dalam merancang dengan melakukan perbaikan terhadap desain rancangan agar mendapatkan hasil rancangan yang sesuai kebutuhan.

\section{Konsep Rancangan}

Wahana Permainan dan Hiburan Berbasis Teknologi Digital di Surabaya merupakan tempat rekreasi dan hiburan yang semua wahananya berbasis teknologi digital dan ditujukan kepada masyarakat Surabaya. Wahana Permainan dan Hiburan Berbasis Teknologi Digital ini menerapkan tema arsitektur high tech, sehingga pemilihan makro konsep yang sesuai dengan tema adalah bangunan pintar. Tema dan makro konsep akan diterapkan pada obyek rancangan, sehingga menghasilkan rancangan yang baik dan optimal.

Bangunan pintar sebagai makro konsep digunakan agar dapat menciptakan tempat yang berfungsi untuk mewadahi aktivitas bermain dengan wahana yang membutuhkan energi listrik yang besar, sehingga menggunakan sistem teknologi otomatisasi yang dapat meminimalisir penggunaan listrik agar lebih hemat energi. Namun, tetap memperhatikan faktor kenyamanan, keamanan, dan efisiensi. Bangunan Pintar menerapkan intergrasi teknologi berupa suatu perangkat berteknologi otomatisasi yang hemat energi meliputi utilitas, keamanan, dan telekomunikasi bangunan yang memungkinkan dapat diprogam sesuai kebutuhan dan dapat dikontrol secara terpusat serta dilakukan secara otomatis. Setelah menetapkan makro konsep yang dibutuhkan, maka makro konsep dibagi menjadi tiga mikro konsep yaitu mikro konsep tatanan lahan, mikro konsep bentuk, dan mikro konsep ruang. 
Mikro konsep tatanan lahan " Responsif" menciptakan tatanan lahan yang dapat dengan cepat menanggapi suatu kondisi lingkungan berdasarkan iklim. Tatanan lahan dibuat berdasarkan hasil analisis tapak yang menyesuaikan dengan kondisi lingkungan dan iklim di Surabaya. Pola tata massa bangunan dibuat saling terintegrasi agar dapat menanggapi aktivitas penggunanya dengan cepat dan dapat mengakses semua fasilitas dengan mudah. Tatanan lahan tersebut dibuat agar penggunanya dapat merasakan kenyamanan.

Wujud dari penerapan mikro konsep tatanan lahan "Responsif" adalah membuat sirkulasi yang jelas, terarah, dan komunikatif. Orientasi bangunan dibuat saling mengikat dan terhubung dengan taman sebagai perantaranya. Tata massa bangunan terintegrasi dengan zonifikasi tapak yang efektif dan efisien (Gambar 5). Menata landscape dengan menambahkan elemen-elemen hardscape dan softscape yang dapat mengatasi permasalahan iklim.

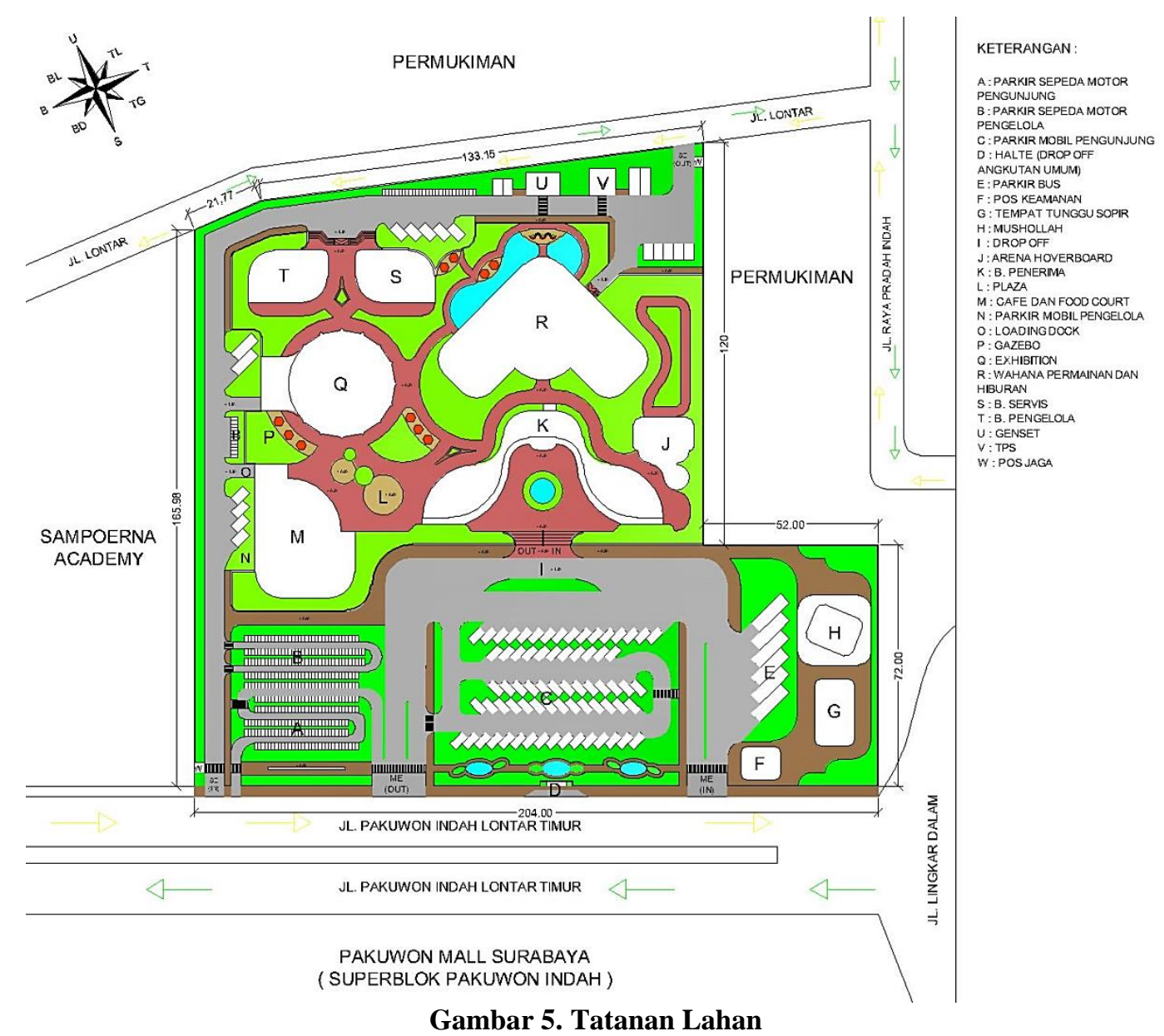

Mikro konsep bentuk "Ekspresif" menciptakan bentuk yang mampu menarik minat pengunjung dengan cara mengolah bentuk, fasad bangunan, dan struktur bangunan. Bangunan agar dapat terlihat ekspresif dengan bentuk yang dapat menggambarkan dan menampilkan struktur bangunan yang terekspose dan pemilihan material yang mampu meningkatkan nilai estetika bangunan sehingga, dapat menunjukkan karakteristik dari arsitektur high tech. Kemudian, menerapkan pendekatan dari makro konsep bangunan pintar dengan cara menggunakan material fasad berteknologi yang mampu menghemat pemakaian energi listrik pada bangunan.

Wujud dari penerapan mikro konsep bentuk "Ekspresif" adalah mengolah bentuk-bentuk geometri dan unsur desain, namun tetap memperhatikan kondisi iklim. Menampilkan struktur pada eksterior bangunan. Lebih banyak menggunakan material dari aluminium, baja dan kaca. Menerapkan warna-warna cerah dan metallic. Memberikan kesan transparan pada bangunan. Pada fasad bangunan 
menggunakan material yang berteknologi untuk mendukung bangunan dalam menghemat energi (Gambar 6 dan 7).

Material berteknologi yang dimaksudkan adalah: (1) Pada jendela menggunakan material kaca laminasi. Kaca laminasi merupakan kaca yang terdiri dari 2 atau lebih lapisan dengan satu atau lebih lapisan transparan dengan penambahan bahan plastic polyvinyl butiral (PVB) diantara kedua lapisannya. Kelebihan dari kaca laminasi adalah dapat mengurangi resiko retakan atau pecah, penghalang kebisingan, dapat mengurangi dan menahan masuknya panas dan sinar ultraviolet ke dalam bangunan sampai $99 \%$. Ruang yang menggunakan kaca laminasi akan terjaga suhu ruangnya sehingga, dapat meminimalisir pemakaian air conditioning (AC) (Lestari \& Alhamdani, 2014). (2) Untuk dinding menggunakan dua macam material yaitu material bata ringan dan sandwich panel. (a) Material bata ringan memiliki pori-pori yang menurunkan berat massa bata sehingga, mampu menyerap panas di luar bangunan dengan tetap mempertahankan suhu dingin di dalam ruang. Selain itu, bata ringan mampu menghalangi dan mengurangi suara bising yang masuk ke dalam ruangan (Dekoruma, 2018a). (b) Material sandwich panel merupakan panel yang terdiri dari tiga lapisan, dengan dua lapisan tipis disebut lapisan kulit atau penutup dan satu lapisan tengah yang tebal disebut lapisan inti. Material lapisan tersebut adalah pelat zincalume untuk lapisan penutup dan lapisan insulasi untuk lapisan inti. Oleh karena itu, sandwich panel memiliki kelebihan yang dapat meredam suara dengan baik, dapat mengurangi panas matahari yang masuk dan pada dinding panel bagian dalam dapat memantulkan cahaya lampu dengan baik. Sandwich panel dinilai mampu untuk mengurangi penggunaan air conditioning $(A C)$ dan listrik (Eprocurement, 2020).

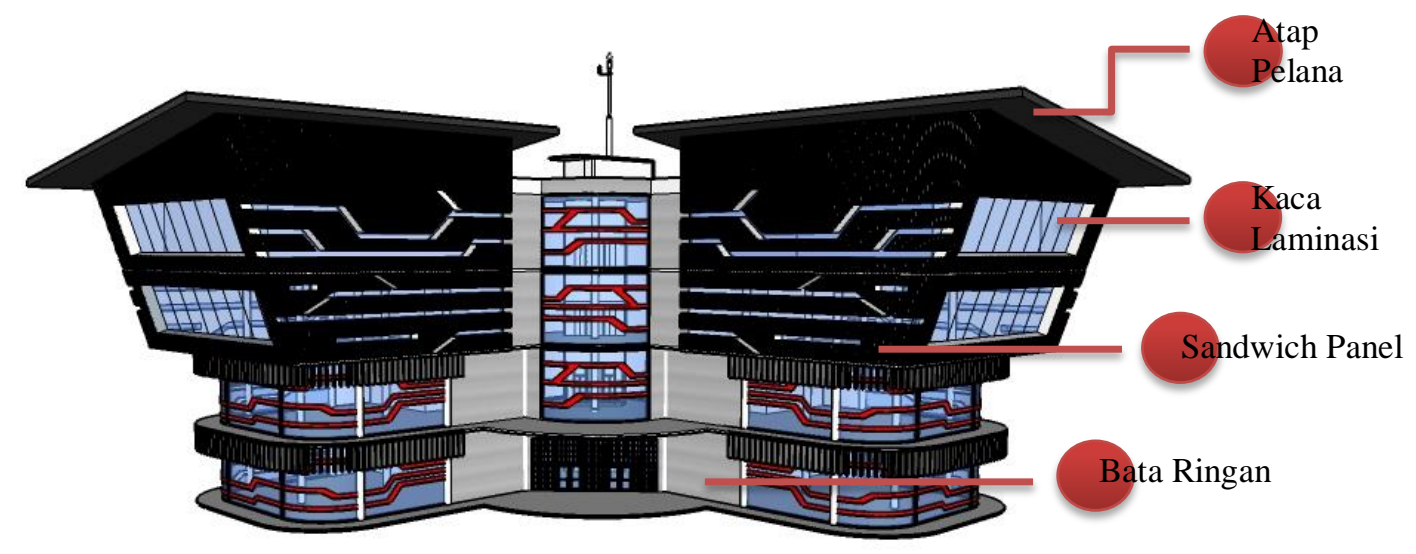

Gambar 6. Bentuk Bangunan Wahana Permainan dan Hiburan

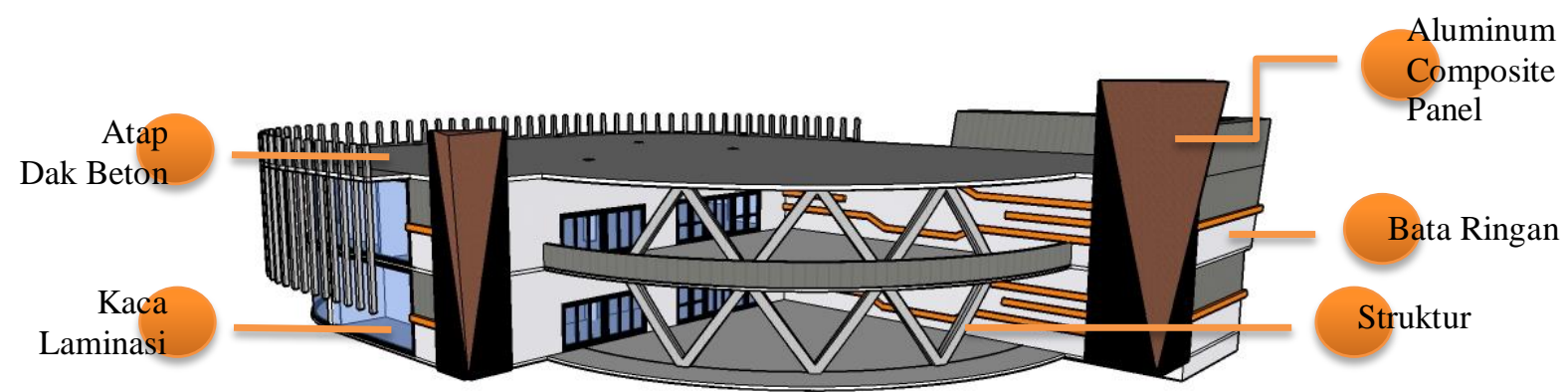

Gambar 7. Bentuk Bangunan Café dan Food Court

Mikro konsep ruang "Futuristik dan Efisien" adalah menciptakan ruang yang dapat memberikan kesan akan masa depan pada desain interior, sehingga pengunjug merasa terkesan dan tidak merasa bosan. Ruang tersebut menggunakan sistem teknologi yang dapat mengoptimalkan performa bangunan dan efisien terhadap penggunaan sumber listrik. Ruang yang dapat meminimalisir penggunaan listrik 
juga dapat meminimalkan biaya operasional dari wahana permainan dan hiburan. Selain itu, mampu menciptakan ruang yang menyediakan berbagai macam ruang yang sesuai fungsinya dan mampu menciptakan ruang memberikan kesan aman, nyaman, dan menyenangkan.

Wujud dari penerapan mikro konsep ruang "Futuristik dan Efisien" adalah desain interior ruang yang futuristik dengan menerapkan bentuk lengkung atau lancip yang dominan, unsur garis seperti papan sirkuit komputer, perpaduan dua warna yang kontras, dan material bertekstur licin dan mengkilap (Dekoruma, 2018b) sebagaimana (Gambar 8). Menggunakan teknologi yang memiliki kemudahan dalam pengoperasian, dan perawatan sistem, serta mampu menghemat energi. Untuk pencahayaan menggunakan lampu LED yang hemat energi. Membuat cross ventilation berupa bukaan jendela yang diletakan saling berhadapan untuk memperlancar sirkulasi udara dan meminimalisir penggunaan air conditioning $(A C)$. Memberikan kesan ruang nyaman dan menyenangkan supaya pengunjung tidak mudah bosan.

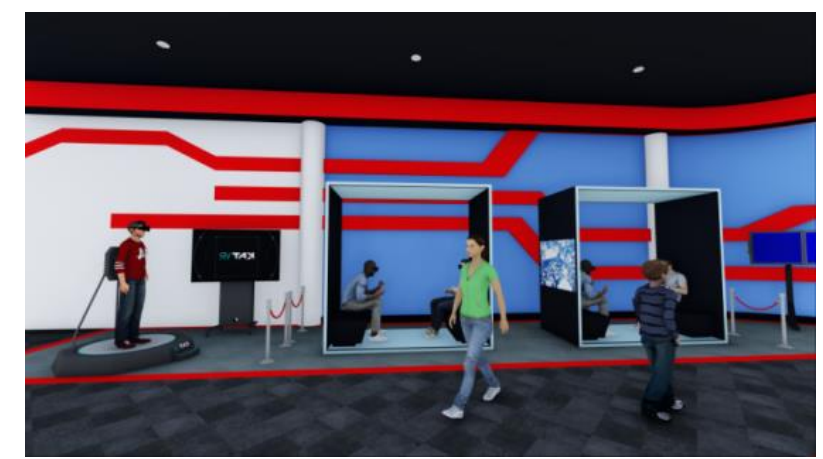

Gambar 8. Interior Ruang Wahana Permainan dan Hiburan

\section{Kesimpulan dan Saran Kesimpulan}

Hasil desain rancangan Wahana Permainan dan Hiburan Berbasis Teknologi Digital di Surabaya berdasarkan dari kajian studi banding baik dari studi banding lapangan dan studi banding literatur. Hasil desain tersebut mampu menggambarkan desain rancangan Wahana Permainan dan Hiburan Berbasis Teknologi Digital di Surabaya dengan lebih baik, sehingga memiliki beberapa keunikan desain, antara lain: (1) Keunikan desain pada tatanan lahan yaitu lebih menonjolkan desain rancangan yang mampu menyesuaikan dengan kondisi lingkungan atau iklim pada tapak dan menata massa bangunan agar pengunjung dapat mengakses dengan cepat dan mudah. (2) Keunikan desain pada bentuk terletak pada penggunaan struktur yang terekspose dan pemilihan material fasad bangunan berteknologi yang mampu meminimalisir penggunaan listrik. (3) Keunikan desain pada ruang terletak pada desain interior yang menciptakan suasana ruang seakan-akan berada di masa depan dan menerapkan sistem teknologi utilitas yang mampu menghemat pemakaian energi listrik.

Dengan adanya bangunan Wahana Permainan dan Hiburan Berbasis Teknologi Digital di Surabaya ini diharapkan mampu menarik minat masyarakat Surabaya untuk datang dan menikmati semua wahana dan fasilitas yang disediakan. Wahana Permainan dan Hiburan Berbasis Teknologi Digital di Surabaya diharapkan juga dapat menjadi pusat tempat bermain permainan dan hiburan berteknologi digital.

\section{Saran}

Ketika proses merancang sebaiknya tema dan konsep yang telah ditentukan dapat diterapkan semaksimal mungkin agar mendapatkan hasil desain yang benar-benar menggambarkan objek rancangan sebagai tempat wisata rekreasi.

\section{Referensi}

Dekoruma, K. (2018a). 5 Keuntungan Membangun Rumah dengan Bata Ringan. Diakses 21 Februari 2021, dari https://www.dekoruma.com/artikel/76834/kelebihan-bata-ringan

Dekoruma, K. (2018b). 8 Ciri Desain Futuristik, Gaya Desain Interior Masa Depan. Diakses 21 Februari 2021, dari https://www.dekoruma.com/artikel/66939/gaya-desain-futuristik 
Depdiknas. 2008. Kamus Besar Bahasa Indonesia. Jakarta: Gramedia Pustaka Utama.

Eprocurement, P. (2020). Kenali Jenis dan Kelebihan Sandwich Panel Sebagai Alternatif Dinding Modern. Diakses 21 Februari 2021, dari https://www.pengadaan.web.id/2020/05/jenis-dankelebihan-sandwich-panel.html

Lestari, L., \& Alhamdani, M. R. (2014). Penerapan Material Kaca dalam Arsitektur. Langkau Betang, $1(2), 30-42$.

Pambudi, E. (2015). 16 Pengertian Teknologi Menurut Para Ahli. Diakses 2 Mei 2021, dari https://www.google.co.id/amp/s/dosenit.com/kuliah-it/teknologi-informasi/pengertianteknologi-menurut-para-ahli/amp

Phoibe, J., Perdana, R, K., Puspitasari L., Utami, P, M., Nur'aini, D, M., Rizky, M., Alverdo, M., dan Karim, R, M. (2015). Psikologi \& Teknlogi Internet Entertaiment. Diakses 2 Mei 2021, dari https://www.google.co.id/amp/s/dosenit.com/kuliah-it/teknologi-informasi/pengertianteknologi-menurut-para-ahli/amp

Pratasik, A. I., \& Sangkertadi. (2011). Arsitektur Pintar. Media Matrasain, 8(2), 16-28.

Pustakapaud. (2016). Definisi Permainan \& Manfaat Bermain Bagi Pembelajaran Anak. Diakses 2 Mei 2021, dari https://pustakapaud.blogspot.com/2016/08/definisi-permainan-manfaat-bermainbagi-pembelajaran-anak.html?m=1

Telew, M., \& Lintong, S. (2011). Arsitektur High Tech. Media Matrasain, 8(2), 94-106. 